\title{
КРАУДИНВЕСТИНГ КАК НОВЫЙ СПОСОБ ФИНАНСИРОВАНИЯ ИННОВАЦИОННЫХ ПРОЕКТОВ
}

\author{
(c) 2018 Перепёлкин Вячеслав Александрович \\ доктор экономических наук, профессор кафедры мировой экономики \\ Самарский государственный экономический университет \\ 443090, г. Самара, ул. Советской армии, 141 \\ E-mail: slavaap@rambler.ru \\ () 2018 Фролова Кристина Алексеевна \\ Самарский государственный экономический университет \\ 443090, г. Самара, ул. Советской армии, 141 \\ E-mail: kitty-kriska@mail.ru \\ (c) 2018 Мухамадиева Лилия Наильевна \\ Самарский государственный экономический университет \\ 443090, г. Самара, ул. Советской армии, 141 \\ E-mail: muhamadievalilli@mail.ru
}

В статье подвергнут изучению краудинвестинг в качестве перспективного способа осуществления финансирования инновационных проектов. Проанализированы особенности краудинвестинга, его виды, потенциал применения в современных российских экономических условиях.

Ключевые слова: краудинвестинг, краудлендинг, стартап, инвесторы, краудинвестинговая площадка, микрофинансирование.

Развитие цифровых технологий и созданных на их основе средств коммуникации расширили спектр применяемых инструментов финансирования экономической деятельности, одним из новейших среди которых выступает краудинвестинг. Последний особенно актуален для малого инновационного бизнеса, лишенного доступа к финансированию с фондового рынка и ограниченного в получении средств от банков, хотя бы в в силу отсутствия кредитной истории [6].

Представляя собой нацеленный на финансовое участие в предпринимательских проектах, вид краудфандинга предполагает уже не безвозмездную помощь, а возврат предоставленных средств с дополнительной платой за их использование. Инвесторы получают долю в компании, рассчитывая на будущие прибыли или на заранее оговоренную величину дохода. Термины краудфандинг и краудинвестинг начинаются со слова «крауд», означающего «толпа, коллектив». В первом случае «толпа» лишь предоставляет для реализации проекта денежные средства, во втором - она инвестирует в проект. Разница состоит в том, что как своеобразное народное финансирование краудфандинг не предполагает прямого участия в развитии стартапа вкладчиков, всего лишь стремящихся поддержать на- чинающего предпринимателя с его интересной идеей [8]. Все, на что могут рассчитывать финансовые доноры проекта - это первыми приобрести созданный продукт по сниженной цене или получить подарки, привилегии.

В научной литературе краудинвестинг часто именуют акционерным краудфандингом, позволяющим на этапе становления стартапа привлечь внешнее финансирование для его реализации со стороны большого количества так называемых микроинвесторов, по отдельности обладающими небольшими суммами денег для вложений [2]. Субъектами процесса краудинвестинга здесь выступают: во-первых, создатели стартапа, нуждающиеся в деньгах на развитие и продвижение предпринимательского проекта инновационного содержания; во-вторых, верящие в хорошую перспективу стартапа микроинвесторы, готовые вкладывать в него пусть и небольшие, но реальные деньги; в-третьих, специализированные площадки - выступающие в роли посредников, благодаря которым находят друг друга организаторы проектов и инвесторы.

Краудинвестинговые площадки прежде всего дают оценку ищущим финансирования инновационным компаниям, выявляя и отсеи- 
вая мошеннические проекты. Важной задачей этих платформ также является контроль выплат прибылей вкладчикам и, в случае прекращения стартапом выплат, оказание помощи инвесторам в возврате вложенных средств. Источником дохода краудинвестинговых площадок выступает комиссионное вознаграждение от инвестируемой компания, в зависимости от площадки и конкретной сделки варьирующееся в пределах от 1 до 6,7\% от общей суммы инвестиций. Первой в мире краудинвестинговой площадкой в 2005 г. стала британская Zора. Год спустя в США появилась аналогичного назначения платформа под названием Prosper. Возникшая вскоре платформа Lending Club в 2014 г. провела IPO, принесшее ей около 5,4 млрд. долл. США.

В настоящее время наиболее популярными краудинвестинговыми площадками являются британские CrowdCube и Seedrs, американские Rabble и AngelList, германская Smava, израильская OurCrowd. В целом в США сегодня насчитывается более 340 площадок коллективного инвестирования, в Великобритании их больше 80, во Франции около полусотни. $\mathrm{B}$ России первой краудинвестинговой платформой стал появившийся осенью 2012 г. SmartMarket, менее чем через год прекративший свое существование. Позже ее судьбу повторили платформы VCStart, WeShare, закрывшиеся в 2015 г.. Пожалуй, самой известной из функционирующих ныне в данном бизнесе российских площадок является, начавшая работать в 2013 г. StartTrack. Как и любой инновационный бизнес, посредничество в процессе краудинвестинга представляет собой высокорискованную деятельность, успех в которой зависит не только от квалификации ее организаторов, но и от существования в достаточной степени благоприятной экономической и институциональной сред для ее ведения. В этом отношении Россия располагает большим потенциалом роста объемов рассматриваемой формы инвестирования, реализация которого будет происходить вместе с накоплением человеческого капитала и последующим усилением инновационной активности в экономике. В качестве примера можно привести экономику США, где активно развивающая технологические новшества Калифорния предложила рынку столько проектов, сколько НьюЙорк, Флорида, Техас и Иллинойс вместе взятые.

$\mathrm{K}$ настоящему времени в краудинвестинге широкое применение получило народное кредитование или краудлендинг, когда помимо возвращения вложенной суммы начисляется фиксированный процент прибыли [4]. Здесь четко оговаривается, когда и на каких условиях будут возвращены средства. Реже применяются роялти, позволяющие инвесторам рассчитывать на часть прибыли в случае успешности проекта, а размер вознаграждения ставится в зависимость от величины инвестиций. Такой вариант краудинвестинга популярен в мире искусства и развлечений, а именно, при съемках фильмов, записях музыкальных произведений, разработке компьютерных игр.

Стартовавший в 2012 г. в США подъем краудинвестинговой деятельности связывают со вступлением в силу закона о финансировании стартапов (Jumpstart Our Business Startups Act), регулярно вносимые поправки в который (подобные принятию третьей статьи, разрешающей мелким инвесторам данным способом инвестировать компании) обеспечивают либерализизацию условий осуществления рассматриваемой деятельности. Развернули сотрудничество с краудинвестинговыми площадками институциональные инвесторы, вкладывающие в проекты крупные суммы [7]. В 2015-2018 гг. число краудинвестинговых сделок стало меньше, но зато увеличился их средняя стоимость и совокупный объем вложений инвесторов. Так, в первый год после JOBS act с предложениями на краудфандинговые платформы вышло более 4700 компаний, а за последний год - только 550. Зато за первый год компаниями было привлечено 385 млн. долл., а за третий -603 млн. долл. Соответственно, вырос средний размер успешного размещения - с 405000 до 731000 долл., при этом “средний чек” от одного инвестора составлял от \$10000 до \$100000 долл. В результате, если в первый год после принятия в США JOBS act запланированную сумму получали 20,2\% компаний, то по итогам последних 12 месяцев этот показатель вырос до 30, 5\%. То есть вначале необходимые средства от инвесторов собирал каждый пятый проект, теперь - каждый третий. Пока подобных нормативных актов в России нет, хотя есть надежда на принятие внесенного весной 2018 г. законопроекта «Об альтернативных способах привлечения инвестиций». Пока же по сравнению с западным, российский краудинвестинг развит существенно слабее: за два последних года 28 российских стартапов привлекли через платформу StartTrack 507 млн. рублей 
или меньше 8 млн. долл. США. На платформе зарегистрирован 1261 инвестор, тогда как почти каждая из 16 американских платформ имеет десятки тысяч зарегистрированных инвесторов.

Впрочем, в последние годы объемы рынка краудинвестинга в нашей стране растут рекордными темпами: согласно оценке Банка России, объем вложений здесь за период 2015-2017 гг. увеличился в 7,9 раза - до 1,8 млрд. рублей [3]. Объективных причин такого рывка две: во-первых, банки пятый год подряд не наращивают и без того скромный портфель кредитования малого и среднего бизнеса, к тому же в до 80\% случаев отказывая соответствующим потенциальным заемщикам; во-вторых, инвесторам всё сложнее получить приемлемую доходность в классических инструментах, в частности, в депозитах в долларах США или в рублях. Поэтому все больше компаний и индивидуальных инвесторов ищут и находят альтернативу банкам в краудинвестинге (табл. 1). Условиями получения денег от инвесторов площадки выступают наличие положительных результатов деятельности компании на рынке и подтвержденный прогнозный спрос на ее товары.

Однако выбор вариантов при осуществлении краудинвестинга в российской экономике пока невелик [1], прежде всего из-за немногочисленности отечественных краудинвестинговых платформ. Среди них наибольшей популярностью пользуются следующие [5]:

1. StartTrack, работающая с 2013 г. как аналог британской Angellist. Минимальная сумма инвестиций составляет 100000 руб., а доходность - до 25\%. Предпочитает работать с фир- мами, ежемесячная выручка которых стартует от 10 млн. руб. и позволяет как приобретать доли в проектах, так и давать деньги предпринимателям в долг.

2. «Город денег» также работает с займами, но ограничивает только минимальный размер финансирования суммой в 50 тыс. руб. 79\% компаний, получивших финансирование через эту площадку, работают в сфере торговли или иных услуг.

3. «Поток», являющийся проектом Альфа-Банка, установил минимальную сумму, которую необходимо продержать хотя бы в течение полугода, на уровне в 10000 руб. Банк обещает доходность равную 30\% годовых;

4. Venture Club. Более $94 \%$ совокупного оборота данной площадки приходится на инвестиции в капитал, но площадка также предлагает клиентам частное финансирование по прямому договору займа. При этом все клиенты Venture Club являются информационно-коммуникационными компаниями, работающими в сферах Consumer Internet, SAS, В2B SAS и Hardware.

Сегодня представляются реальными три направления развития российского краудинвестинга:

1. Кооперация с банками. Краудинвестинговые площадки предлагают банкам привлекать частное финансирование для юридических лиц, которым отказали в банковском кредите или выдали кредит в недостаточном объеме. Например, «Уралсиб» предлагает клиентам воспользоваться услугами площадки StartTrack. Банкам выгодно предлагать клиентам частное финансирование, чтобы повысить лояльность заемщи-

Таблица 1. Динамика показателей краудинвестирования в России

\begin{tabular}{|l|c|c|c|}
\hline \multicolumn{1}{|c|}{ Показатели } & 2015 г. & 2016 г. & 2017 г. \\
\hline Инвестиции в капитал (млн.руб.) & 232 & 1505,5 & 1837,7 \\
\hline Профинансировано компаний & 81 & 277 & 871 \\
\hline Количество инвесторов & 105 & 1313 & 14466 \\
\hline
\end{tabular}

Источник. Ресурс: https://incrussia.ru/understand/infografika-kak-ustroen-rynok-kraudinvestinga-v-rossii.

Таблица 2. Объем привлеченных инвестиций на некоторых российских краудинвестинговых площадках

\begin{tabular}{|l|c|c|c|}
\hline \multicolumn{1}{|c|}{ Название компании } & $\begin{array}{c}\text { Объем инвестиций, } \\
\text { млн. руб. }\end{array}$ & Площадка & Сфера деятельности \\
\hline Футибол & 352,4 & StartTrack & Спорт \\
\hline Интернет-магазин детских товаров & 3,1 & Город Денег & E-commerce \\
\hline GetShop TV & 45 & Venture Club & Реклама \\
\hline
\end{tabular}

Источник. Ресурс: https://incrussia.ru/understand/infografika-kak-ustroen-rynok-kraudinvestinga-v-rossii/ 
ков и минимизировать кредитные риски.

2. Увеличение числа инвесторов. Количество людей, которые совершили не менее одной сделки через краудинвестинговые площадки, за 2017 г. выросло более чем в 11 раз - до 14 тыс. человек. Вместе с тем, краудинвестинговым инструментам присуща низкая ликвидность, поскольку инвестору можно выйти из проекта не в любой момент. Для не умеющих планировать людей это является существенным ограничением.

3. Повышение уровня насыщения рынка и специализация. Работая по одной модели, российские компании стараются создать уникальный продукт и делают акцент на различных объемах финансирования и различных типах корпоративных клиентов. Специализация, низ- кое насыщение рынка и отсутствие специального регулирования позволяют краудинвестинговым площадкам избегать прямой конкуренции и даже сотрудничать (например, рекомендуя инвесторам либо реципиентам, не подошедшим по критериям, другие площадки).

Таким образом, выбор при краудинвестинге в современной России весть между соответствующими западными платформами и немногочисленными отечественными сервисами. При этом одни эксперты утверждают, что начинающему бизнесу бессмысленно выходить на западные краудинвестинговые площадки без проверки своей эффективности на Родине. Другие, наоборот, предрекают скорый бум краудинвестинга и предлагают юридически легальные варианты обхода законодательных барьеров.

\section{Библиографический список}

1. Зейналов А.А. Практика применения краудтехнологий в Российской Федерации / А.А. Зейналов, Ю.М. Грузина, Д.А. Ильенков // Современная наука. Серия Экономика и право. 2016. № 11. С.41-45

2. Нешитой А.С. Финансы и кредит: Учебник / А.С. Нешитой. 6-е изд., перераб. и доп. Москва. 2011. 576 с.

3. Богомолова А. Инфографика: как устроен рынок краудинвестинга в России. 2017. Режим доступа: https:// incrussia.ru/understand/infografika-kak-ustroen-rynok-kraudinvestinga-v-rossii/, свободный.

4. Евдокимов С.С., Кобышев М.С. Современные модели финансирования стартапов // Финансы и кредит. 2017. Режим доступа: https://cyberleninka.ru/article/n/sovremennye-modeli-finansirovaniya-startapov, свободный.

5. Соколов И.Н., Солохин А.А., Фияксель Э.А. Сравнительный анализ российских краудинвестинговых платформ // Инновации. 2017. Режим доступа: https://cyberleninka.ru/article/n/sravnitelnyy-analiz-rossiyskihkraudinvestingovyh-platform, свободный.

6. Фияксель Э.А., Солохин А.А., Соколов И.Н. Краудинвестинг. Обзор исследований и промежуточные результаты развития // Инновации. 2017. Режим доступа: https://cyberleninka.ru/article/n/kraudinvesting-obzorissledovaniy-i-promezhutochnye-rezultaty-razvitiya, свободный.

7. Hornuf L., Schwienbacher A. Funding dynamics in crowdinvesting // Research Papers in Economics. № 9(15). 2015. Режим доступа: https://www.econstor.eu/handle/10419/121440, свободный.

8. Schondorfer S., Ebert T. The crowdinvestor - What drives investors' decision-making to participate in crowdinvesting? // COPENHAGEN BUSINESS SCHOOL. 2014. Режим доступа: http://studenttheses.cbs.dk/ bitstream/handle/10417/5083/tim_ebert_og_simone_schöndorfer.pdf?sequence=1, свободный. 